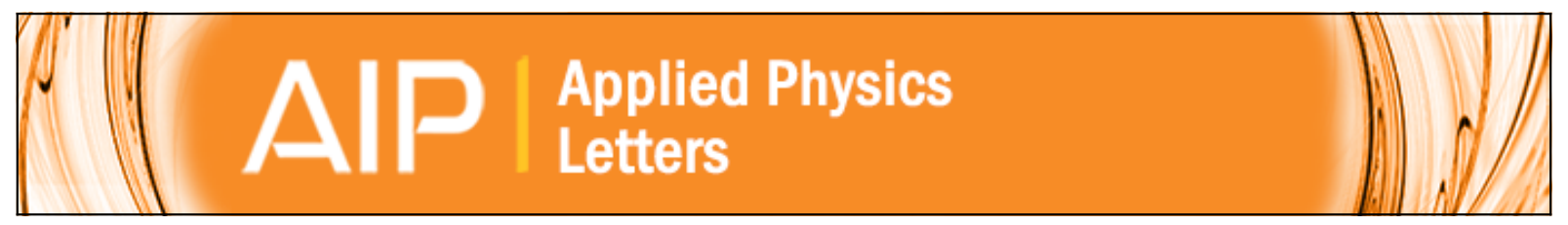

\title{
Laser-induced exfoliation of amorphous carbon layer on an individual multiwall carbon nanotube
}

G. Singh, P. Rice, K. E. Hurst, J. H. Lehman, and R. L. Mahajan

Citation: Applied Physics Letters 91, 033101 (2007); doi: 10.1063/1.2756357

View online: http://dx.doi.org/10.1063/1.2756357

View Table of Contents: http://scitation.aip.org/content/aip/journal/apl/91/3?ver=pdfcov

Published by the AIP Publishing

\section{Articles you may be interested in}

Carbon nanotube formation by laser direct writing

Appl. Phys. Lett. 93, 023108 (2008); 10.1063/1.2959061

Substitution reactions of carbon nanotube template

Appl. Phys. Lett. 88, 223105 (2006); 10.1063/1.2208548

Catalytical growth of carbon nanotubes/fibers from nanocatalysts prepared by laser pulverization of nickel sulfate J. Appl. Phys. 99, 024312 (2006); 10.1063/1.2165403

In situ growth of nanowire on the tip of a carbon nanotube under strong electric field Appl. Phys. Lett. 86, 133103 (2005); 10.1063/1.1879090

Processing of individual carbon nanotubes-cutting and joining

AIP Conf. Proc. 590, 285 (2001); 10.1063/1.1420110

\section{AlP Re-register for Table of Content Alerts}

\section{Create a profile. \\ Sign up today!}

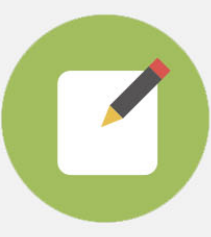




\title{
Laser-induced exfoliation of amorphous carbon layer on an individual multiwall carbon nanotube
}

\author{
G. Singh ${ }^{\mathrm{a})}$ and P. Rice \\ Mechanical Engineering Department, University of Colorado at Boulder, Colorado 80309 \\ K. E. Hurst and J. H. Lehman \\ National Institute of Standards and Technology, Boulder, Colorado 80305 \\ R. L. Mahajan \\ Institute for Critical Technology and Applied Science, Virginia Polytechnic Institute and State University, \\ Blacksburg, Virginia 24061
}

(Received 30 April 2007; accepted 18 June 2007; published online 16 July 2007)

\begin{abstract}
Pulsed laser treatment of an individual multiwall carbon nanotube induced selective exfoliation of the amorphous carbon contamination layer. The multiwall carbon nanotube (MWCNT) was exposed to a $248 \mathrm{~nm}$ excimer laser. After the treatment, transmission electron microscopy images show that the amorphous layer has expanded and separated from the crystalline MWCNT walls. This interesting observation has implications for laser cleaning and possible thinning of MWCNTs to reduce the radial dimensions. (C) 2007 American Institute of Physics. [DOI: 10.1063/1.2756357]
\end{abstract}

Carbon nanotubes have been the focus of interest ever since they were first discovered in $1991 .{ }^{1}$ The exceptional mechanical and electronic properties of carbon nanotubes are a result of their unique crystalline structure. However, to exploit these properties, a growing number of applications require them to be the impurities and defect-free. One of the most common impurities observed in as-prepared CNTs is an amorphous carbon layer that can envelope the CNT along its length. This amorphous carbon layer can arise from several sources; carbon from the growth process not incorporated into the nanotube can be deposited on the surface of the nanotube if the temperature and precursor gas proportions are not optimized for contaminant-free nanotubes. Also, during the purification process hydrocarbon contaminants in the solvents can condense on the nanotube and vitrify, depending on the following treatments. Finally, imaging the nanotube in the scanning electron microscope can deposit a contamination layer that is generated from hydrocarbon residue typically found inside most scanning electron microscopy (SEM) vacuum chambers.

Numerous techniques have been employed to remove unwanted carbon species and catalysts. Catalysts have been removed by dissolution in acid baths and high-temperature vacuum annealing. ${ }^{2,3}$ The removal of carbon species has been, however, much more challenging due to the fact that the desired material, such as the unwanted material, is also carbon but in a slightly different form. The techniques to remove the unwanted carbon species include washing the material in different solvents, acid treatment, and thermal oxidation of the material. ${ }^{4,5}$ Thermal oxidation can be induced by furnace heating in various atmospheres or heating with high-powered lasers.

In our work, we have focused on purification by laser treatment of the nanotubes. We have developed a technique of selective removal or destruction of carbon nanotubes by laser excitation in resonance with interband transition characteristic to specific tube types. In a previous paper, Hurst

${ }^{a)}$ Electronic mail: gsingh@colorado.edu et al. ${ }^{6}$ have shown purification and removal of non-nanotube carbon impurities from bulk single-walled nanotubes (SWNTs) without destruction of the SWNTs by the use of $248 \mathrm{~nm}$ excited resonance laser. The removal of the impurities was attributed to resonant excitation of the pi plasmon, which facilitated the oxidation of neighboring carbonaceous impurities. Ozone generated from the ionization of oxygen by the excimer laser was speculated to play an important role in this process. Simmons et $\mathrm{al}^{7}$ showed an increase in Raman $D$-band to $G$-band ratio for SWNTs with increased ozone exposure time, which was attributed to the creation of defects on CNT side wall.

Based on the findings in Refs. 6 and 7 on bulk samples, we have attempted characterizing the effect of the $248 \mathrm{~nm}$ laser treatment on an individual multiwalled carbon nanotube (MWCNT). We are particularly interested in the removal of carbon impurities coating of the outer tube wall and ultimately in selectively removing outer tube walls.

Our sample consisted of a single MWCNT placed with a three-axis micromanipulator and welded to a $\mathrm{Cu}$ transmission electron microscope (TEM) grid by electron beam induced deposition in a SEM. ${ }^{8}$ The MWCNT diameter was approximately $70 \mathrm{~nm}$. The MWCNT was welded so it would bridge a gap on the TEM grid and be freestanding between the welds (Fig. 1). The MWCNT used in this study was synthesized by chemical vapor deposition on a thin-film Fe catalyst. Precursor gases were xylene and ferrocene, and the furnace temperature during synthesis was $725^{\circ} \mathrm{C}$. The nanotubes were removed from the growth substrate and suspended in toluene. They were subsequently dried into a mat so that individual nanotubes were readily accessible to be moved and finally welded to the TEM grid by use of the micromanipulator.

TEM images were then taken along the length of the nanotube before laser treatment, and an intrinsic feature in the MWCNT was located for position reference after the laser exposure. For this experiment the intrinsic feature was a large bulge of amorphous carbon, probably deposited during the welding process. The welded MWCNT sample was then exposed in atmosphere at room temperature to the laser ra- 


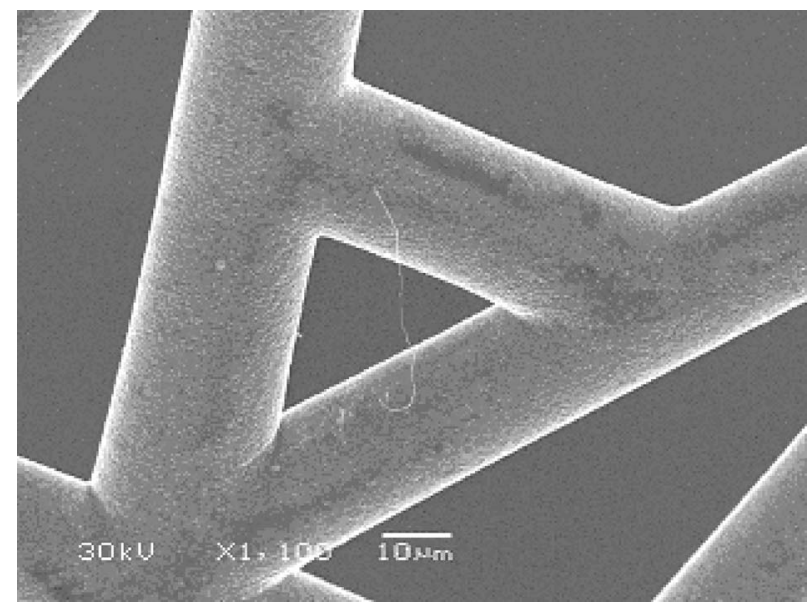

FIG. 1. SEM image of the individual freestanding MWNT, welded to the $\mathrm{Cu}$ TEM grid.

diation $(\sim 5 \mathrm{eV})$, operating at a pulse repetition frequency of $10 \mathrm{~Hz}$ and a pulse length of approximately $20 \mathrm{~ns}$. The exposure was done with an average power of $650 \mathrm{~mW} / \mathrm{cm}^{2}$ for $3 \mathrm{~min}$. A precalibrated thermopile detector was used for measuring the average beam power. The spot size of the beam, as measured by pyroelectric array detector, was approximately $1 \mathrm{~cm}^{2}$; therefore, the exposure area covered the entire TEM grid, which is a disk $3 \mathrm{~mm}$ in diameter. Similar to the procedure described by Hurst et al., ${ }^{6}$ the average grid temperature was measured with an optical pyrometer. Finally, TEM images were taken at the reference position and compared with pretreatment images for any visible structural modifications.

Figure 2 shows a high resolution image of a typical MWCNT, from the batch, showing the details of the amorphous carbon coating that was approximately $5-7 \mathrm{~nm}$ in thickness. High resolution imaging of the laser treated nanotube itself was limited due to the vibration stability of the MWCNT, which made microscope focusing difficult at higher magnification. Parallel graphitic fringes confirming the crystalline CNT structure were seen only in thinner portions of the MWCNT near the outer tube walls.

The main observation from our TEM analysis of the MWCNT before and after exposure was the separation or

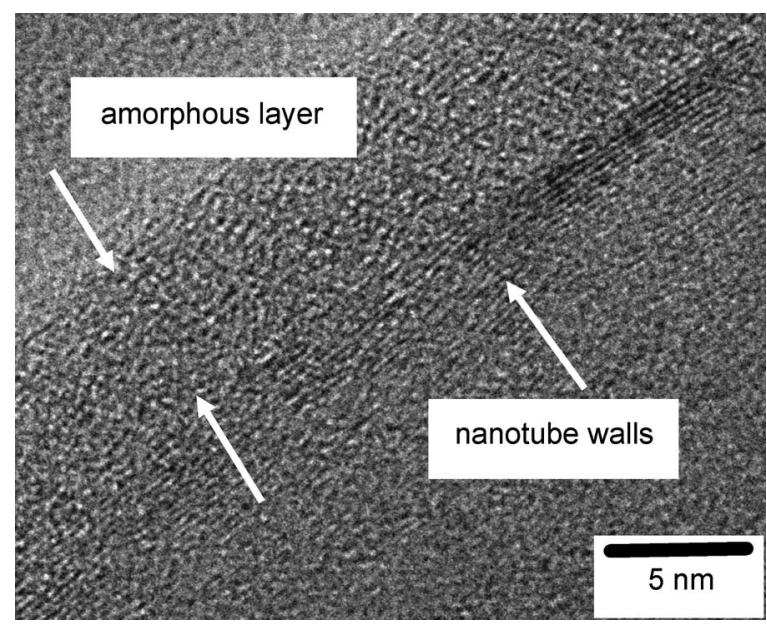

FIG. 2. TEM image showing the amorphous carbon layer on the outer surface of a typical MWCNT used in this study Also seen are parallel graphitic fringes that correspond to the walls.
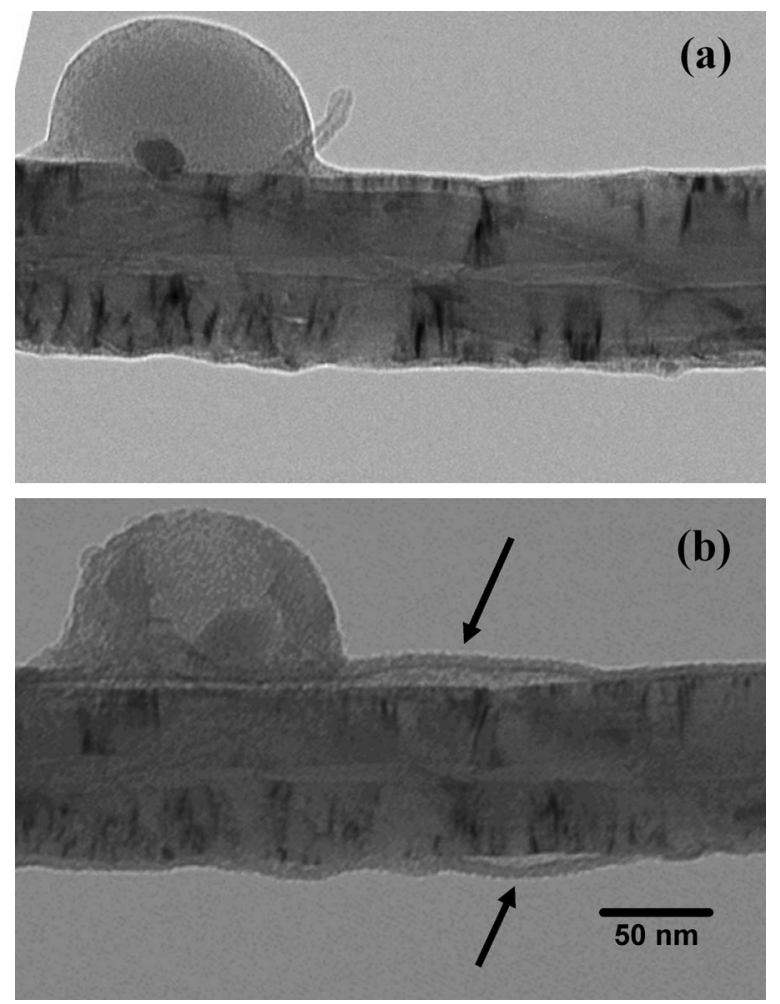

FIG. 3. TEM images showing the same region on the MWNT (a) immediately after welding to the TEM grid and (b) after laser treatment. The hemispherical protrusion was an intrinsic feature used to locate the same region after treatment. The arrows indicate areas where the amorphous carbon layer separated from the MWNT.

exfoliation of the amorphous carbon coating from the nanotube walls, as shown in Fig. 3. We observed this effect along the length of the nanotube; however, locating the same area before and after the treatment was difficult, as the TEM imaging was not done in situ and also the nanotube is long $(\sim 15 \mu \mathrm{m})$ which makes it impractical to collect so many TEM images for comparison.

Our premise is that this separation is due to differential expansion between the amorphous carbon layer and the MWCNT outer shell. The resulting exfoliation can be attributed to two factors, which may be acting simultaneously; these are pi-plasmon resonance and thermal mismatch. The amorphous impurity envelope is a result of physical deposition of carbonaceous material (either during processing or handling of the MWCNT in the SEM); hence it is very likely for it to be attached to the MWCNT with weak physical bonds. Pi plasmon represents the collective excitation of the pi electron system and is observed to be $\sim 5-7 \mathrm{eV}$ (overlaps the $248 \mathrm{~nm}$ excimer laser for graphitic carbon $\left.{ }^{9,10}\right)$. Electron energy loss spectroscopy shows that pi-plasmon energy for multiwalled carbon nanotubes depends on the growth process and decreases with a decrease in diameter. ${ }^{11,12}$ Therefore we think that a pi-plasmon resonance carries suitable photon energy that can transfer momentum to the impurity-CNT interface bonding orbitals that make the impurities prone to oxidation and weaken the physical adhesion between the amorphous layer and the MWCNT.

The final exfoliation could be the result of thermal stresses originating from the sudden temperature rise with each laser pulse. MWCNTs have a negative coefficient of thermal expansion (CTE) of $\sim-1.3 \times 10^{-6} \mathrm{~K}^{-1}$ along the length direction ${ }^{13}$ and hence tend to contract, while the amor- 
phous carbon layer surrounding the MWCNT has a positive CTE value of $2 \times 10^{-6}-7 \times 10^{-6} \mathrm{~K}^{-1}$ and tries to expand. ${ }^{14}$ Although a relatively low rise in average grid temperature $\left(\sim 100^{\circ} \mathrm{C}\right)$ was observed, there exists the possibility of a high instantaneous temperature change. This implies a cyclic thermal loading, resulting in a thermal mismatch between the contracting MWCNT and the expanding coating with each laser pulse, resulting in a state of differential in-plane stress and relaxation.

In addition, the separation is not uniform and the thickness of the coating is not significantly changed. Also, it is difficult to make a complete before and after comparison of the whole MWCNT, due to the fact that some of the intrinsic features, which were originally seen in the "as-prepared" MWCNT, have been removed during the laser treatment. However, we have observed sporadic areas of exfoliation of the amorphous layer along the whole length of the CNT. Casual inspection of these images also seems to indicate no large changes in the defects in the MWCNT. Nevertheless, higher resolution studies must be conducted in order to verify this assumption.

In conclusion, the use of a $248 \mathrm{~nm}$ wavelength $(\sim 5 \mathrm{eV})$ excimer laser has been shown to selectively exfoliate the non-nanotube impurities (mostly amorphous carbon) surrounding an individual MWCNT. Three-dimensional micromanipulation of individual CNT and attachment to the grid enabled TEM imaging of an individual nanotube all along the length. Comparison of TEM data before and after the treatment provides evidences of singularities that were not previously understood in bulk samples and can now be characterized as a partial separation of the amorphous impurity surrounding the MWCNT outer shell. This partial separation has been attributed to the thermal mismatch between the amorphous and crystalline carbon due to the photon en- ergy carried by the excimer laser that is dissipated in breaking or loosening physical bonds at the interface. Finally, with further work, we will attempt to completely eliminate this impurity coating by increasing the peak pulse power of the laser, as well as treating the MWCNT in a furnace in an ozone over-pressure atmosphere.

Thanks are due to J. R. McIntosh, Mary Morphew, Cindi Schwartz, and Gary Zito for training and for using the TEM.

${ }^{1}$ S. Iijima, Nature (London) 354, 56 (1991).

${ }^{2}$ W. Huang, Y. Wang, G. Luo, and F. Wei, Carbon 41, 2585 (2003).

${ }^{3}$ A. G. Rinzler, J. Liu, H. Dai, P. Nikolaev, C. B. Huffman, F. J. RodríguezMacías, P. J. Boul, A. H. Lu, D. Heymann, D. T. Colbert, R. S. Lee, J. E. Fischer, A. M. Rao, P. C. Eklund, and R. E. Smalley, Appl. Phys. A: Mater. Sci. Process. 67, 29 (1998).

${ }^{4}$ M. T. Martinez, M. A. Callejas, A. M. Benito, M. Cochet, T. Seeger, A. Anson, J. Schreiber, C. Gordon, C. Marhic, O. Chauvet, and W. K. Maser, Nanotechnology 14, 691 (2003).

${ }^{5}$ B. Bendjemil, E. Borowiak-Palen, A. Graff, T. Pichler, M. Guerioune, J. Fink, and M. Knupfer, Appl. Phys. A: Mater. Sci. Process. 78, 3 (2004).

${ }^{6}$ K. E. Hurst, A. C. Dillon, D. A. Keenan, and J. H. Lehman, Chem. Phys. Lett. 433, 301 (2007).

${ }^{7}$ J. M. Simmons, B. M. Nichols, S. E. Baker, M. S. Marcus, O. M. Castellini, C. S. Lee, R. J. Hamers, and M. A. Eriksson, J. Phys. Chem. B 110, 7113 (2006).

${ }^{8}$ A. Folch, J. Servat, J. Esteve, J. Tejada, and M. Seco, J. Vac. Sci. Technol. A 14, 2609 (1996).

${ }^{9}$ T. Pichler, M. Knupfer, M. S. Golden, J. Fink, A. Rinzler, and R. E. Smalley, Phys. Rev. Lett. 80, 4729 (1998).

${ }^{10}$ B. J. Landi, H. J. Ruf, C. M. Evans, C. D. Cress, and R. P. Raffaelle, J. Phys. Chem. B 109, 9952 (2005).

${ }^{11}$ P. M. Ajayan, S. Ijima, and T. Ichihashi, Phys. Rev. B 49, 2882 (1994).

${ }^{12}$ M. M. Brzhezinskayaa, E. M. Baitinger, and V. V. Shnitov, Physica B 348, 95 (2004).

${ }^{13}$ Y. K. Kwon, S. Berber, and D. Tomanek, Phys. Rev. Lett. 92, 015901 (2004).

${ }^{14}$ F. C. Marques, R. G. Lacerda, A. Champi, V. Stolojan, D. C. Cox, and S. R. P. Silva, Appl. Phys. Lett. 83, 3099 (2003). 